\title{
The pathology of butterfly densities in uraemia
}

\author{
R. T. H U G HE S ${ }^{1}$ \\ From the Welsh National School of Medicine
}

\begin{abstract}
Seven cases are presented which are considered to throw some light on the pathology of butterfly densities and their pathogenesis. It is shown that reversible butterfly densities may represent pulmonary vascular congestion and readily reabsorbed oedema fluid resulting from fluid retention and increased blood volume (fluid lung). Terminal butterfly densities associated with hypertensive heart failure in uraemia represent variable haemorrhagic and fibrinous pulmonary oedema with secondary cellular changes and organization (uraemic pneumonia). By means of whole lung sections haemorrhagic forms of uraemic pneumonia associated with hypertensive heart disease are shown to be localized to the lung 'medulla', and the relevance of secondary lobular boundaries to the pathological anatomy is demonstrated. It is considered probable that the butterfly distribution is not determined by uraemic factors but by a non-specific haemodynamic mechanism which is relevant to all forms of central pulmonary oedema.
\end{abstract}

The syndromes which are collectively termed uraemias are sometimes associated with radiographic pulmonary opacities showing a distinctive distribution. The classical pattern observed on a postero-anterior film consists of symmetrical densities extending from each lung hilum into the lung fields, leaving clear peripheral zones, apices, and costophrenic angles. In some instances a lateral waist-like indentation is observed. This pattern is known by various descriptive terms: 'butterfly shadows' (Lelong and Bernard, 1937 ; Nessa and Rigler, 1941); 'batswing shadows' (Hodson, 1950) ; 'angel's wing' (Marchand, 1951) ; and 'sunburst shadows' (Allen, 1951). Alternatively, terms implying pathogenesis are sometimes employed: 'pulmonary azotaemia' (Rendich, Levy, and Cove, 1941); 'pulmonary hyperaemia with acidosis' (Drinker, 1945) ; 'uraemic oedema' (Doniach, 1947) ; 'uraemic pneumonia' (Hodson, 1950) ; and 'fluid lung' (Alwall, Lunderquist, and Olsson, 1953 ; Olsson, 1954).

The terminology is confusing because of its variety and because it derives from the separate viewpoints of radiologists and pathologists. There exists some confusion, too, concerning the pathological interpretation of butterfly densities, and the mechanism underlying the anatomical distribution is controversial.

This paper attempts to define the circumstances in which butterfly densities occur in uraemia and

1Present address: Department of Pathology, Bishop Auckland General Hospital, Co. Durham to add to existing knowledge of their pathology and pathological anatomy.

\section{MATERIAL}

Six cases described here were studied at the Cardiff United Hospitals and the Institute of Pathology, Welsh National School of Medicine. Four were taken from a series of 67 patients who died with elevated levels of blood urea and who had had one or both lungs examined by the Gough-Wentworth (Gough and Wentworth, 1960) technique of mounting whole organ sections on paper. Histological blocks were obtained from inflated lung from abnormal areas, each lobe, and sometimes serially from normal to abnormal areas. Large sections and histology were correlated with chest radiographs when available. These four cases are described together with two cases which present radiological features alone. The last case was studied at Belvidere Hospital, Glasgow.

\section{RESULTS}

Examination of chest radiographs in uraemic subjects has shown that the typical symmetrical densities which constitute the butterfly pattern occur in a small proportion of cases and that asymmetrical opacities may sometimes emerge. Opacities which are less well defined but which preserve the perihilar or central distribution also occur. 
Butterfly densities in uraemia may resolve during life or may persist, and provide variable necropsy changes.

RESOLVING OPACITIES In this category two cases are described in which diuresis (in acute glomerulonephritis) and relief of obstruction to the urinary flow (bladder tumour) were associated with clearing of bilateral central opacities.

Case 1 Acute glomerulonephritis A woman aged 42 years was admitted to the Royal Infirmary, Cardiff, on 4 March 1959 with a history of frontal headaches, increasing shortness of breath, and swelling of the face and ankles for five days. She had had an influenza-like illness three weeks before admission. On examination she was breathless at rest, distressed, puffy, and slightly cyanosed. The jugular venous pressure was elevated. The blood pressure was $200 / 100 \mathrm{~mm}$. Hg. The respiratory rate was increased, and diffuse crepitations were heard over both lung fields.

Investigations: Haemoglobin $85 \%$. Blood urea 45 mg./100 ml. The urine was brown and cloudy and contained erythrocytes and albumin.

Her chest radiograph (Fig. 1) showed congestion of both lung fields with faintly mottled opacities in the middle and lower zones showing faint rounded contours beyond which the lungs were relatively clear.
During the course of a few days diuresis resulted in marked clinical improvement, disappearance of signs of congestive heart failure, and resolution of radiographic shadows. The blood pressure fell to $160 / 90 \mathrm{~mm}$. $\mathrm{Hg}$ and the blood urea to $30 \mathrm{mg} . / 100$ $\mathrm{ml}$.

Comment: Noteworthy features in this case were the resolution of bilateral faint butterfly densities following diuresis, and the minimal degree of azotaemia relative to clinical evidence of left ventricular failure.

Case 2 Acute on chronic retention of urine A coalworker aged 62 years was admitted to Llandough Hospital on 23 December 1952 with chronic retention of urine for 12 months, complete retention for seven days, and severe breathlessness for 24 hours. On examination he was extremely ill and orthopnoeic: there was no oedema of the legs or sacrum; the blood pressure was $190 / 115 \mathrm{~mm}$. Hg. Generalized wheezes and crackling sounds were heard over both lungs, and the bladder was distended to the level of the umbilicus. The blood urea was $360 \mathrm{mg}$. $/ 100 \mathrm{ml}$. A chest radiograph on admission (Fig. 2) showed a slightly increased transverse cardiac diameter and bilateral pulmonary opacities more extensive on the right side. The central and perihilar areas showed the greater densities; on the right side the opacity consisted of a dense area adjacent to the cardiac border,

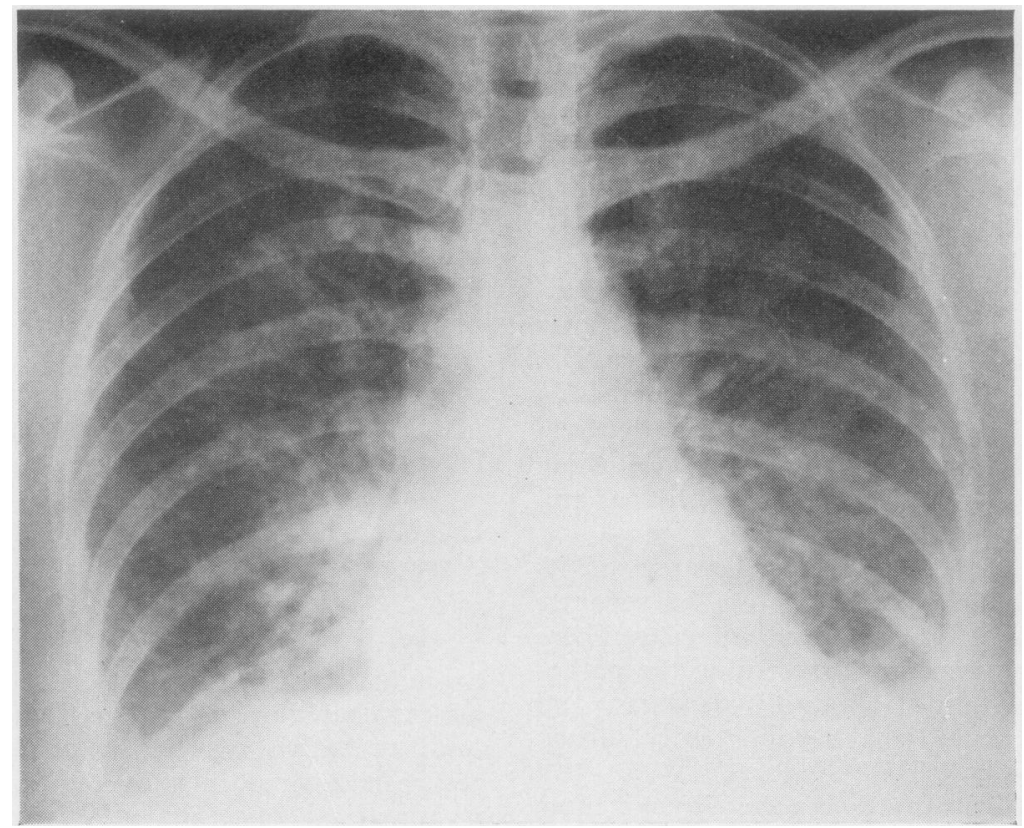

FIG. 1. Case 1. Female aged 42 years. Acute glomerulonephritis, bilateral central oedema, and basal congestion. The central opacity shows a faint rounded demarcation from the clear, upper, peripheral zone. 


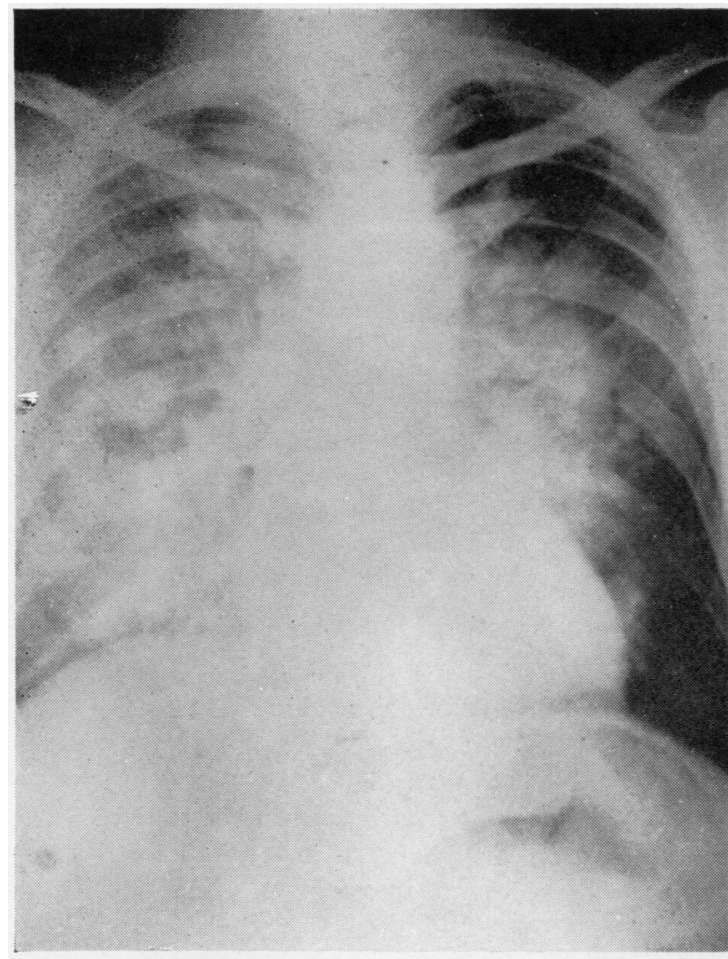

(a)

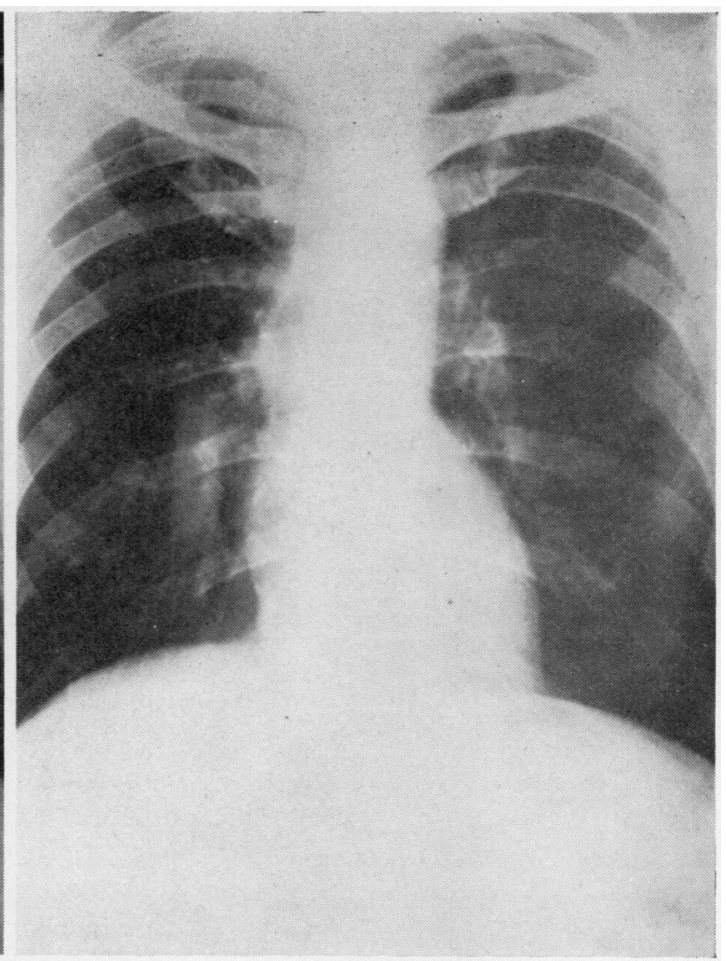

(b)

FIG. 2. Case 2. Male aged 62 years. Acute on chronic retention of urine. Chest radiographs (a) before and (b) after bladder decompression. Blood urea $360 \mathrm{mg} . / 100 \mathrm{ml}$., falling to $210 \mathrm{mg} .1100 \mathrm{ml}$.

demarcated from a less dense shadow proceeding 'fanwise' towards an almost clear periphery.

Following treatment by slow bladder decompression and intravenous aminophylline the chest improved rapidly, and six days later the chest was radiologically clear. The blood urea level fell to $180 \mathrm{mg} . / 100 \mathrm{ml}$., but later rose to $210 \mathrm{mg}$. $/ 100 \mathrm{ml}$.: there was evidence of persistent renal impairment, since the creatinine clearance was $45 \%$ of normal. Suprapubic cystotomy revealed a large, smoothwalled bladder tumour.

Comment: It is noteworthy that symptomatic improvement and complete clearing of radiological densities occurred in the presence of poor renal function and persistent azotaemia.

TERMINAL BUTTERFLY DENSITIES AND RELATED PATHOLOGY The necropsy series of 67 azotaemic patients produced only three good examples of wing-shaped densities with satisfactory postmortem correlation. A fourth case revealed pathological changes with the characteristic butterfly distribution, but a recent chest radiograph was not available. The patients were young adults in the terminal phase of chronic destructive renal disease with severe hypertension and cardiac decompensation.

Case 3 Malignant hypertension A Negro man aged 29 years was admitted to the Royal Infirmary, Cardiff, on 29 November 1955. He had had headache for four years, nocturia for one year, blurring of vision for six months, breathlessness for three months, ankle swelling for three weeks, and had been coughing up blood-stained sputum for three days. On examination there was orthopnoea and oedema of the face, legs, and lumbar and sacral regions. The blood pressure was $250 / 150 \mathrm{~mm}$. $\mathrm{Hg}$, the heart was enlarged to the left, and triple rhythm was audible. The fundi showed papilloedema and haemorrhages. In the chest there were widespread wheezes and basal crepitations.

Investigations: Blood urea $182 \mathrm{mg} . / 100 \mathrm{ml}$. ; haemoglobin 50\%; while cell count 7,800/c.mm.; platelet count $90,000 /$ c.mm. The bleeding time was prolonged in excess of 20 minutes. The urine showed heavy albuminuria, a deposit of many leucocytes and erythrocytes, granular, hyaline, and cellular casts. On the chest radiograph (portable film) (Fig. 3) there were bilateral opacities involving most of the lung fields, excluding the apices and bases with central 


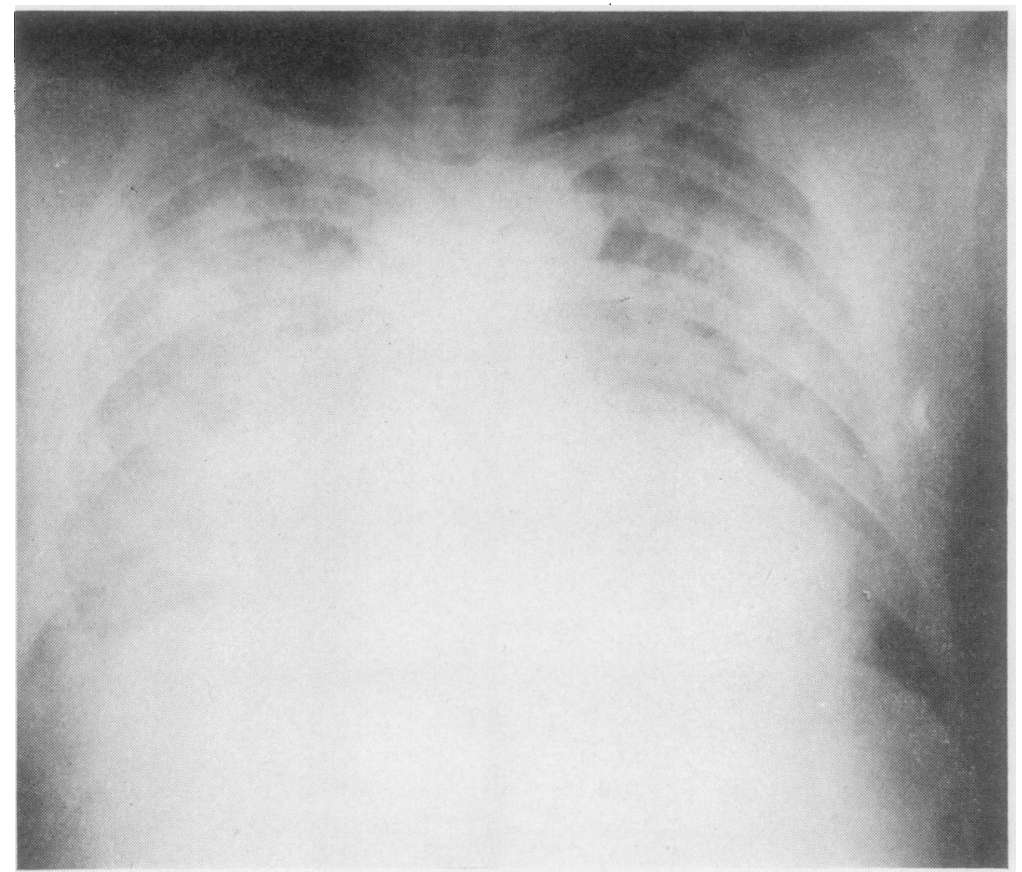

FIG. 3. Case 3. Male aged 29 years. Chest A.P. radiograph (portable film) showing cardiac enlargement of left ventricular type and bilateral opacities with butterfly pattern. Blood urea $182 \mathrm{mg} . / 100 \mathrm{ml}$.

accentuation and right-sided predominance. The heart was enlarged and boot-shaped.

The patient deteriorated with increasing signs of heart failure and died on 2 December 1955.

Necropsy findings: The heart weighed $640 \mathrm{~g}$. and showed marked left ventricular hypertrophy. The kidneys showed histological evidence of malignant hypertension superimposed on 'chronic nephritis'. The lungs were increased in weight (right, $900 \mathrm{~g}$. ; left, 800 g.). The right lung was haemorrhagic and firm in consistency. A large section (Fig. 4) revealed an intensely haemorrhagic process involving most of the lung but sparing a posterior peripheral and anteroinferior rim. The pattern was made up of secondary lobular units, some lobules showing more intense haemorrhages. The anatomical limitation of the gross haemorrhagic process was also determined by lobular boundaries and this applied to the peripheral limitation. Histology of the lung showed, in the central lobules (Fig. 5a), alveolar spaces filled with erythrocytes, interlacing strands of fibrin, and a few macrophages containing haemosiderin. Other fields showed oedema moderately rich in fibrin strands which communicated between adjacent alveoli through alveolar pores. The peripheral zones showed wide oedematous septa and scanty fibrinous alveolar oedema (Fig. 5b).

Comment: In a patient with malignant hypertension, congestive cardiac failure, and uraemia

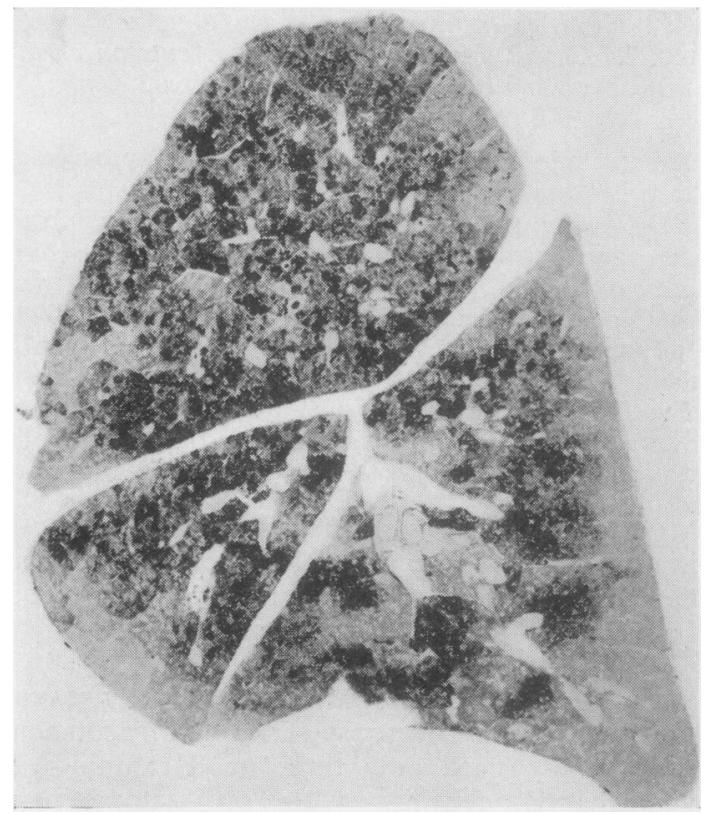

FIG. 4. Case 3. Sagittal mounted section of right lung. Haemorrhagic uraemic pneumonia sparing the posterior antero-inferior margin. Prominent outlines of secondary lobiles. 


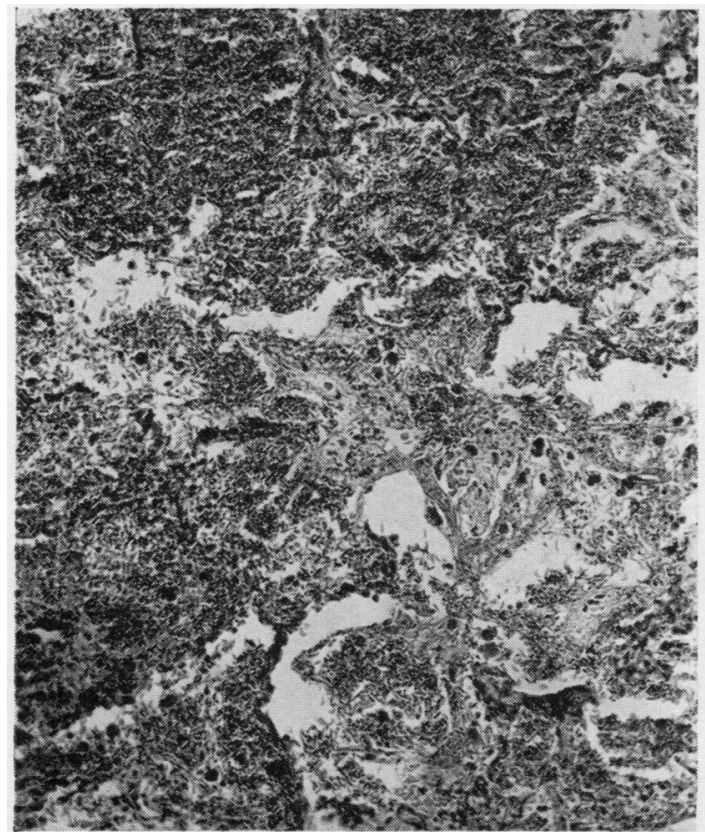

(a)

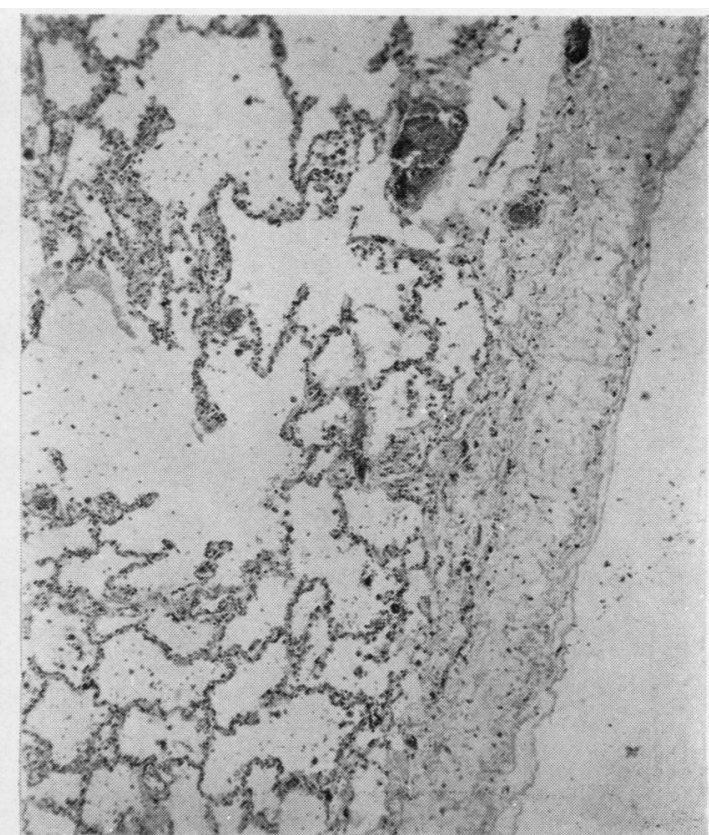

(b)

FIG. 5. Case 3. (a) Central zone of right lung. Alveoli packed with erythrocytes and interlacing fibrin strands. $A$ few darker staining mononuclear cells containing haemosiderin are seen. H. and E. $\times 120 .(b)$ Peripheral zone showing oedematous pleura and scanty alveolar oedema. H. and E. $\times 60$.

with clinical and laboratory evidence of a bleeding tendency, the butterfly densities were caused by severe acute haemorrhagic and fibrinous oedema. The right-sided predominance and the lobular distribution are emphasized.

Case 4 Malignant hypertension A man aged 47 years was admitted on 23 December 1958 complaining of headache for one year and haematuria and nocturia for one month. On examination he was distressed and orthopnoeic, with signs of congestive cardiac failure. The blood pressure was $220 / 140 \mathrm{~mm}$. $\mathrm{Hg}$. The blood urea was $220 \mathrm{mg}$. $/ 100 \mathrm{ml}$. A chest radiograph (Fig. 6) showed a slightly enlarged heart and 'butterfly' opacities of variable density. The right lung was involved to a greater degree than the left and showed prominent interlobular markings (Kerley's B lines) in the peripheral lower zone.

Necropsy findings: The following changes were seen: cardiomegaly due to hypertrophy of the left ventricle; fibrinous pericarditis; pleural effusion; hepatomegaly; and renal changes consistent with the malignant phase of essential hypertension. The right lung weighed $1,120 \mathrm{~g}$., the left $960 \mathrm{~g}$. The main bronchi exuded mucoid fluid. The cut surfaces revealed a firm, rubbery consistency, more marked in the central zones, with foci of haemorrhage and lower lobe congestion (Fig. 7). Histology of the lung showed focal haemorrhages and alveolar albuminous and fibrinous oedema. In some areas fibrin was clumped and showed early organization. In others, casts of alveoli and alveolar ducts were formed of cellular granulomatous tissue. Scanty polymorphonuclear leucocytes were observed, whereas mononuclear cells were more numerous. Some alveoli contained desquamated cells, cubical in shape, forming occasional rosette patterns. One pulmonary arteriole showed fibrinoid necrosis and one bronchial arteriole showed necrosis with intimal sloughing.

Comment: This case of congestive cardiac failure in uraemia demonstrates typical butterfly densities. These were due to mixed albuminous and fibrinous oedema in the perihilar zones with evidence of older organized and hyalinized exudate, i.e., 'sub-acute' pulmonary oedema.

Case 5 Chronic pyelonephritis with malignant hypertension A young woman aged 19 years was admitted to the Cardiff Royal Infirmary on 27 February 1958 . Six months previously she had had an influenza-like illness followed a month later by dyspnoea progressing to nocturnal orthopnoea. She had a dry cough and bruised easily. On examination she was pale and breathless. The heart was slightly enlarged ; the blood pressure was $200 / 100 \mathrm{~mm}$. Hg. The fundi showed early papilloedema. The respiratory system was normal. 


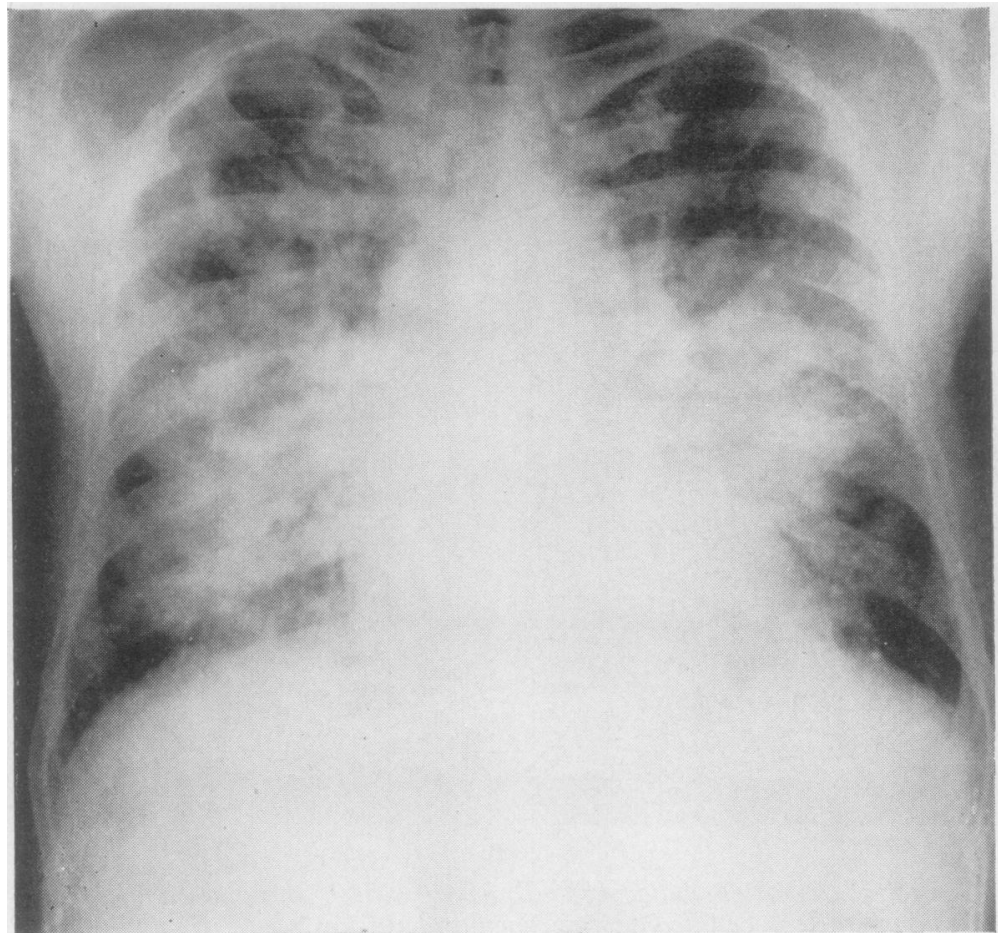

FiG. 6. Case 4. Male aged 47 years. Chest radiograph with characteristic butterfiy opacities (three days before death). Blood urea $220 \mathrm{mg} .100 \mathrm{ml}$.

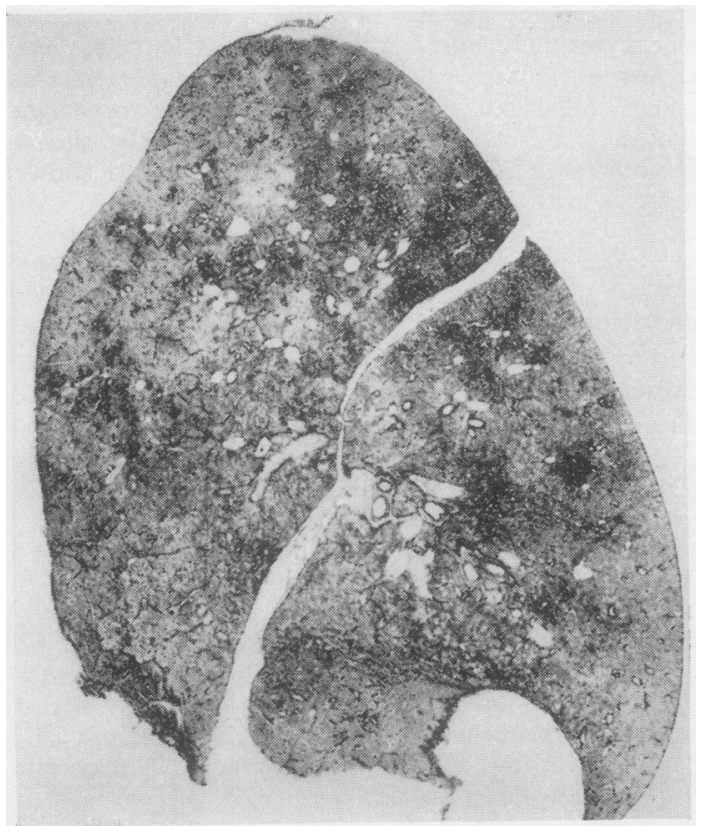

Investigations: Haemoglobin 7.7 g./100 ml. $(52 \%)$; red cells normochromic and normocytic. Blood urea $276 \mathrm{mg}$. $/ 100 \mathrm{ml}$. The urine showed heavy albuminuria and a deposit of 5 to 10 pus cells per $1 / 6$ field. A chest radiograph five days before death (Fig. 8) showed a central opacity in the right lung field adjacent to the right cardiac border, not involving the apex, the lateral lung field, or the base. The $\frac{\text { S }}{2}$ lateral margin of this opacity was well defined and $\supset$ partly linear. The left lung field showed more diffuse soft opacities. Septal lines were present in both costophrenic angles.

Necropsy findings: The heart showed moderate $N$ hypertrophy of the left ventricle. The kidneys were N granular and contracted, with histological evidence of $\omega$ severe destructive disease consistent with chronic pyelonephritis. The lungs were increased in weight, $\bullet$ the cut surface being firm in consistency, dark brown $\mathbb{D}$ in colour, with glistening red and purple foci. A large ? lung section (Fig. 9) showed, in the right lung, focal 0 and confluent haemorrhagic lesions occupying lobular $\stackrel{\vec{\Phi}}{\circ}$

FIG. 7. Case 4. Sagittal mounted section of right lung. $\stackrel{\AA}{\AA}$ Focal haemorrhages and diffuse lower lobe congestion. $\mathbb{\perp}$ The lung weighed $1,120 \mathrm{~g}$. and microscopv revealedo 'sub-acute' organizing fibrinous exudate and extensive albuminous oedema. 


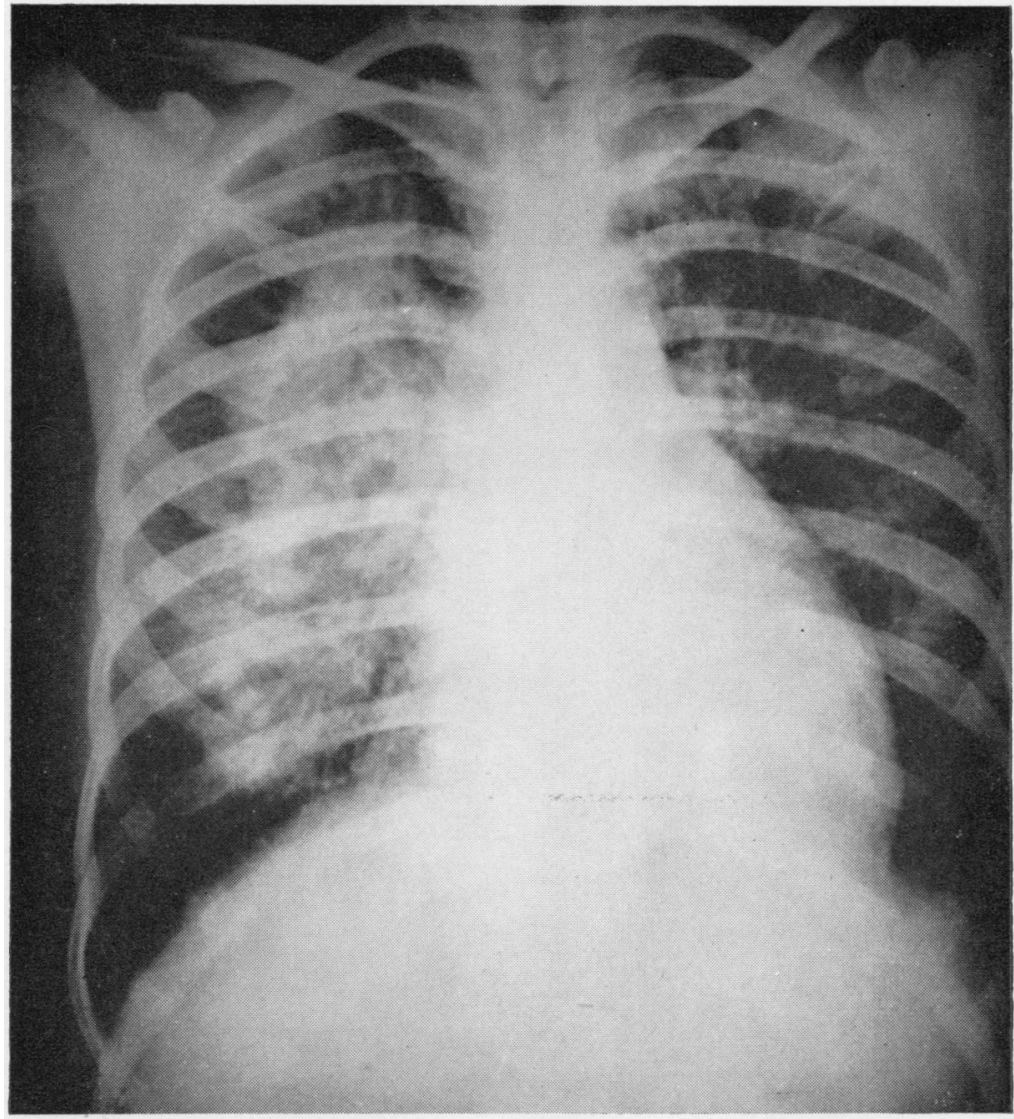

FIG. 8. Case 5. Female aged 19 years. Chest A.P. radiograph taken five days before death. Right side: wing-shaped density and septal lines. Left side : diffuse congestion. Blood urea $276 \mathrm{mg}$. $/ 100 \mathrm{ml}$.

units limited to the major part of the lung centre. The margin separating the central zone from the clear peripheral zone appeared to be formed of distal boundaries of secondary lobules. Microscopy (Figs $10 \mathrm{a}, \mathrm{b}, \mathrm{c})$ showed a subacute fibrinous exudate interspread with empty dilated alveolar ducts and respiratory bronchioles and variable amounts of haemorrhage without haemosiderosis. Fibrin was deposited as filaments, dense coalescent masses with rounded whorled arrangement, and as bands forming a lining to dilated air spaces and simulating "hyaline membrane'. Varying phases of organization were evident and some organized clumps displayed a highly cellular granulomatous structure. In some areas the exudate consisted predominantly of mononuclear and desquamated alveolar cells in progressive stages of disintegration. In between these degenerating cells there was granular eosinophilic material containing nuclear remnants. Aggregations of these cells and granular substance produced a 'fibrinoid' staining property and stained positively with periodic acid
Schiff but not with a conventional fibrin stain (phosphotungstic acid haematoxylin). Polymorphonuclear leucocytes were scanty and vascular lesions were infrequently seen as occasional capillary necrosis and a few thrombi in venous tributaries. Some areas showed capillary congestion. The loose connective tissue surrounding arteries and in the interlobular septa showed broadening by oedema and in some areas appeared mucinous. The left lung (Fig. 11), though not demonstrating the 'medullary' restriction of pathology, showed similar morphological features.

Comment: In this case the central localization of the radiographic density was unilateral and well defined. Histopathology revealed identical features in each lung, i.e., a subacute organizing oedema with terminal haemorrhage and cellular changes. The exudative process was lobular in distribution and the peripheral limitation corresponded with lobular boundaries. 


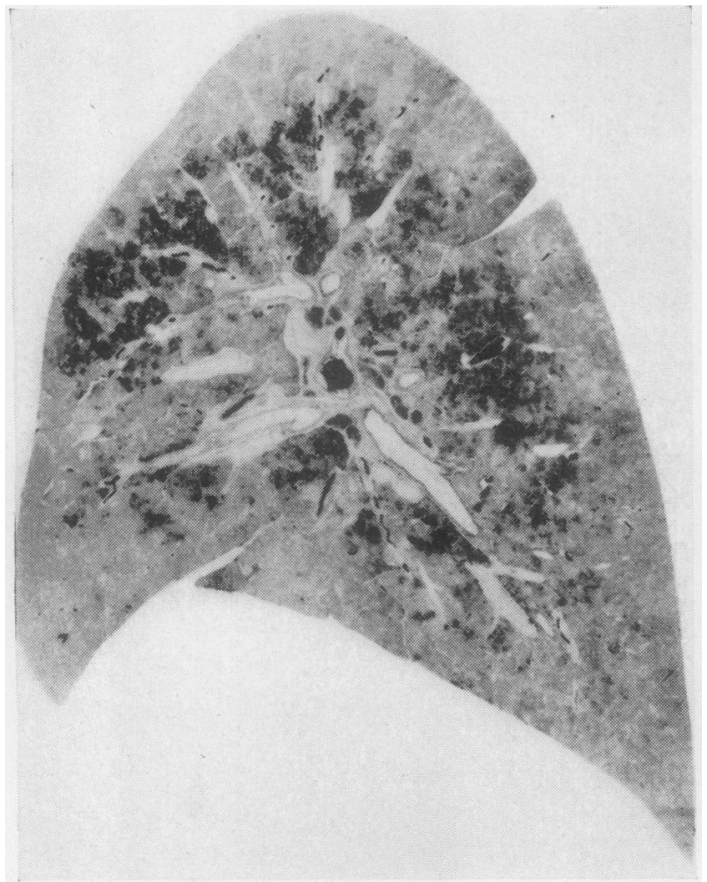

FIG. 9. Case 5. Sagittal section of right lung showing well-defined 'medullary' distribution of uraemic pneumonia with lobslar and confluent haemorrhages.

Case 6 Chronic glomerulonephritis with malignant hypertension A man aged 34 years was admitted on 27 August 1957. He was in uraemic coma with acidotic respiration. Known to have had acute glomerulonephritis 20 years previously, he had been in the chronic phase with severe hypertension for several years.

Investigations: Blood urea $581 \mathrm{mg} . / 100 \mathrm{ml}$. Serum bicarbonate $8 \mathrm{mEq} / 1$.

Radiographic examination: The radiograph 12 days before death (Fig. 12) showed marked cardiac enlargement and a hazy right lower zone opacity adjacent to the right cardiac border.

Necropsy findings: These were as follows: large heart (weight $540 \mathrm{~g}$.) due to hypertrophy of the left ventricle ; congested liver (weight 2,000 g.) ; granular contracted kidneys with severe chronic destructive

FIG. 10. Case 5. (a) (Below) An irregular pattern of alveolar filling interspersed with dilated empty ducts and bronchioles. Interlobular, perivascular, and peribronchiolar oedema. Haemorrhage, e.g., top centre, in relation to venous tributary. Right upper lobe : central zone. $H$. and $E . \times 12$.

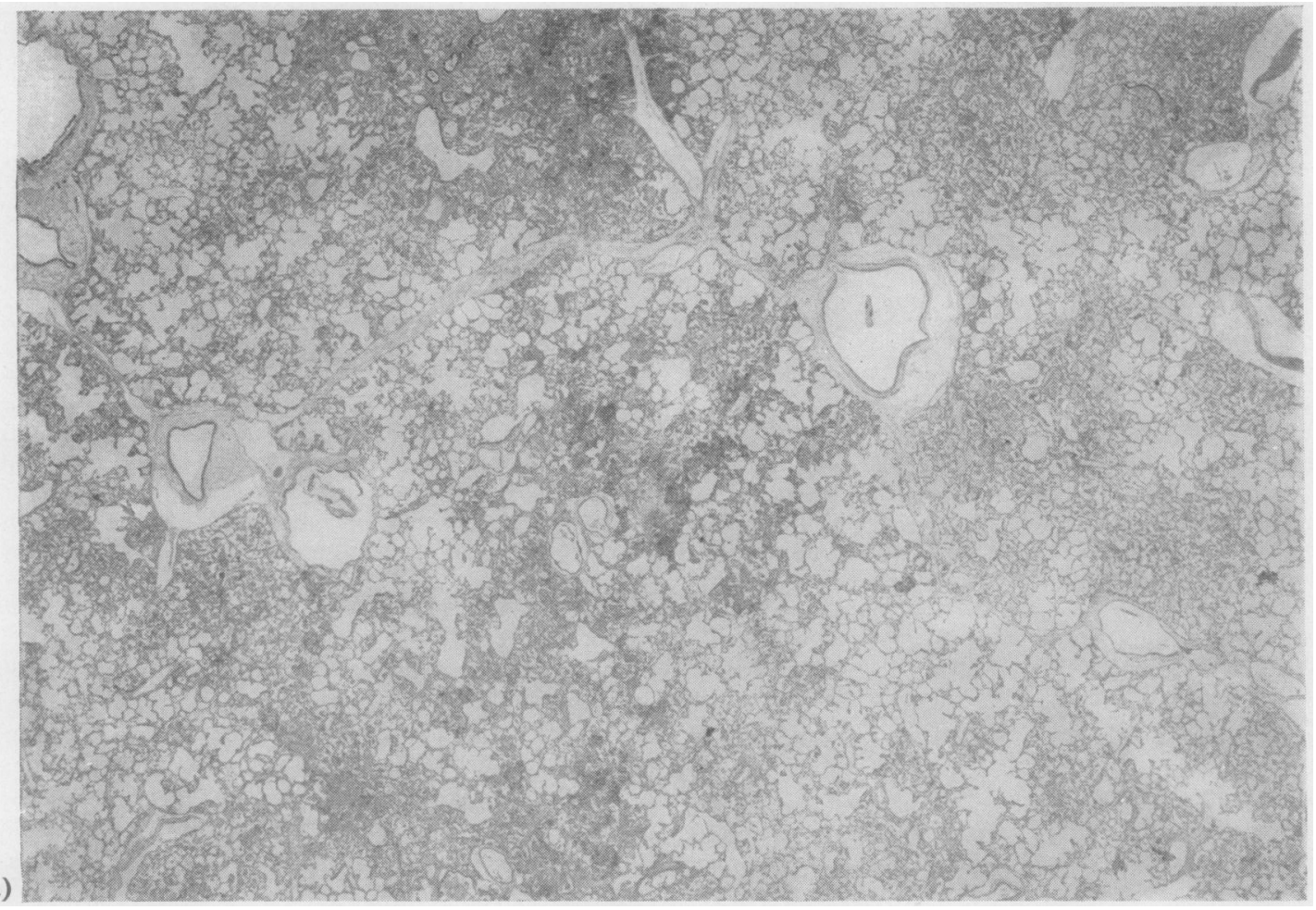

(a) 


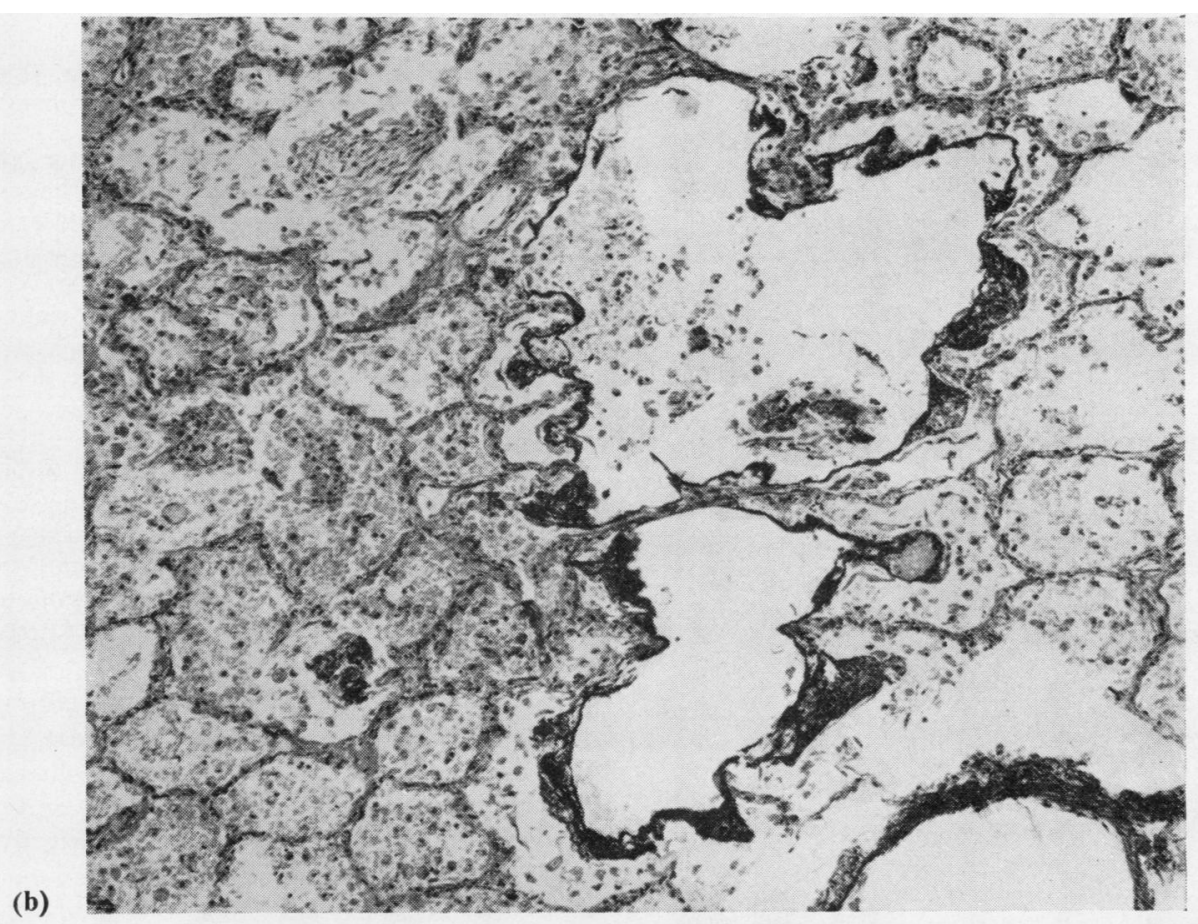

(c)

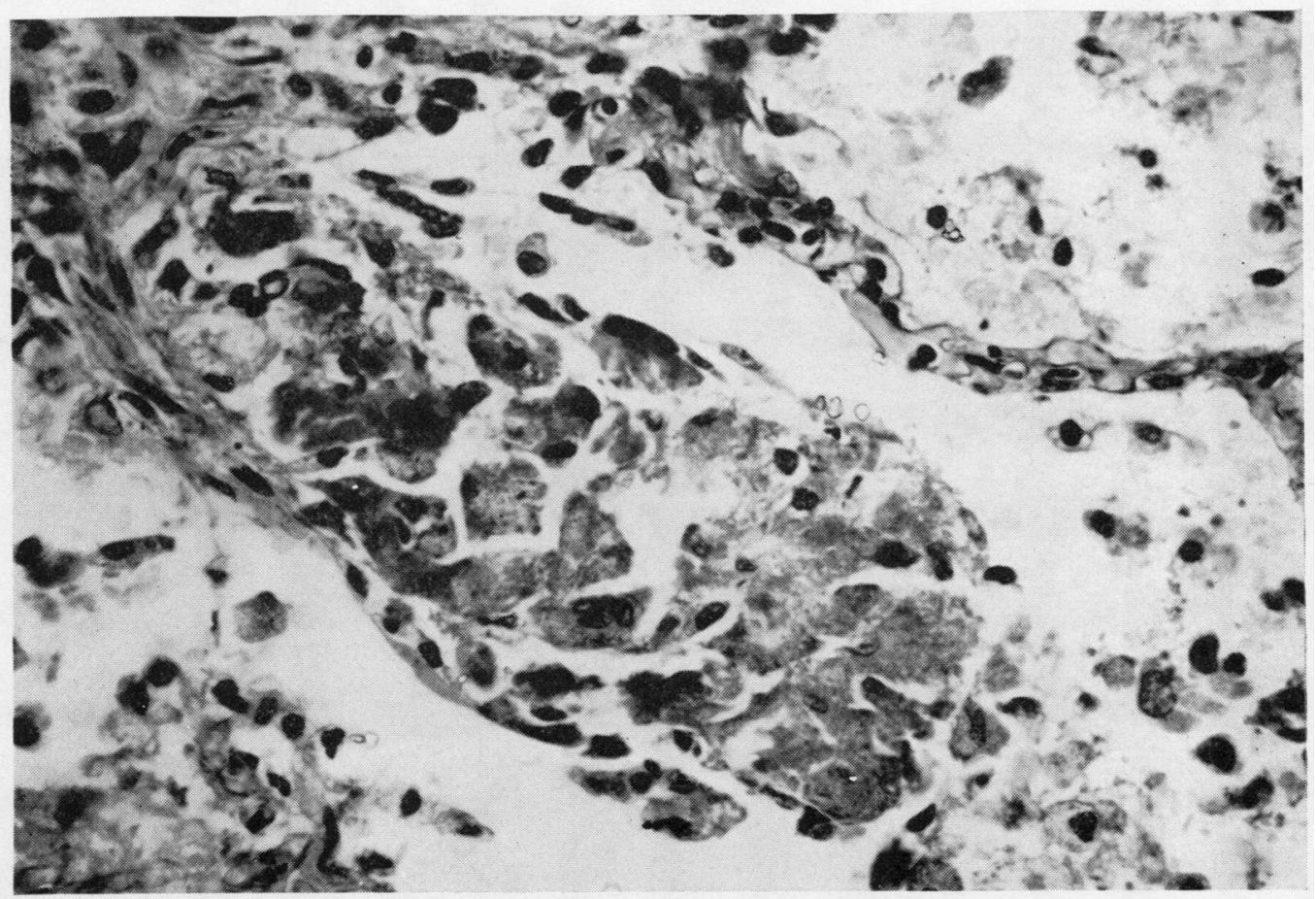

FIG. 10. Case 5. (b) Fibrinous exudate with membranous and clumped arrangement. Organizing clumps of exudate also shown. Right lower lobe. P.T.A.H. $\times 90$. (c) Aggregate of degenerate cells and nuclear debris containing granular P.A.S.-positive material. Early fibroblastic invasion. Periodic acid Schiff. $\times 450$. 


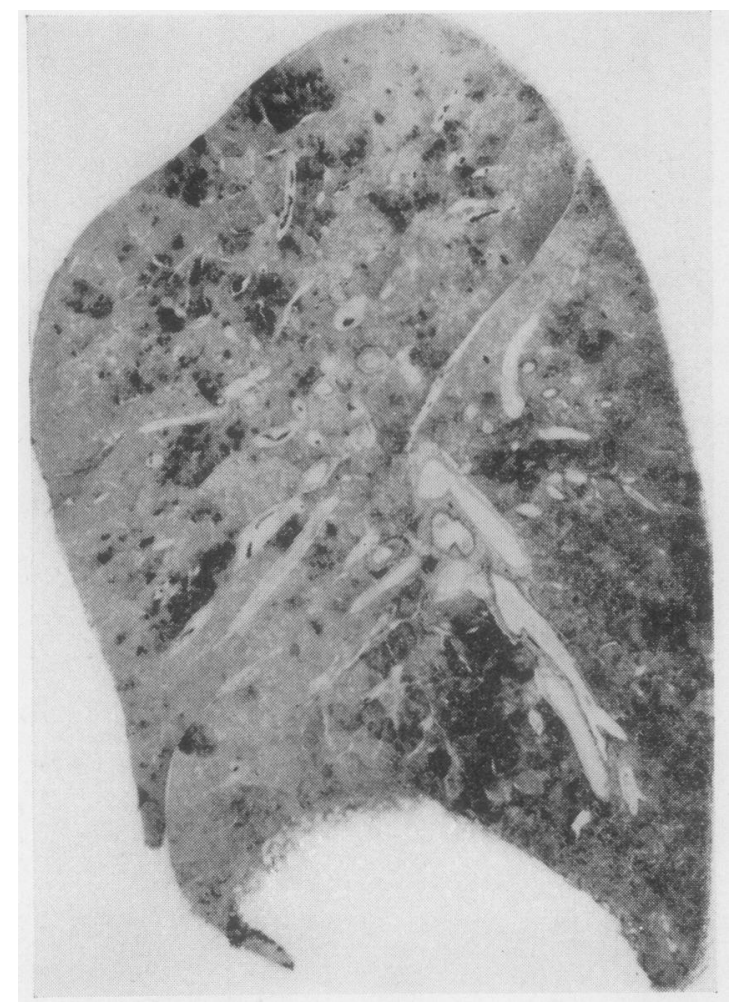

FIG. 11. Case 5. Sagittal section of left lung. Scattered focal and lobular haemorrhages. Lower lobe congestion.

glomerular disease and necrosis of some afferent arterioles; bilateral pulmonary haemorrhages and rubbery consolidation maximal in the perihilar zones.

Large sections (Fig. 13) in the coronal plane showed haemorrhages involving the central zones with spread to interlobar fissures and the right apex. In the main, the peripheral zone was spared to a depth of 1 to $1.5 \mathrm{~cm}$. and in some parts the linear perimeter of secondary lobular boundaries could be discerned.

Microscopy revealed chronic bronchitis, broadened interlobular septa, alveolar and alveolar duct exudate consisting of clumped fibrin and mononuclear cells. In some zones there were organization and foci of older organized exudate (Fig. 14). Some fibrinous and organized material was lined by prominent alveolar epithelial cells.

Comment: This patient had chronic glomerulonephritis with severe hypertensive heart disease and died in uraemic coma. Radiology showed an early right lower zone consolidation, and large lung sections revealed well-defined butterfly distribution of haemorrhagic subacute oedema and evidence of old focal exudates.

\section{DISCUSSION}

The material presented here demonstrates some characteristic examples of butterfly densities and
FIG. 12. Case 6. Male aged 34 years. Chest radiograph 12 days before death showing cardiomegaly and right middle and lower zone density adjacent to cardiac border. Blood urea 581 $\mathrm{mg} . / 100 \mathrm{ml}$.

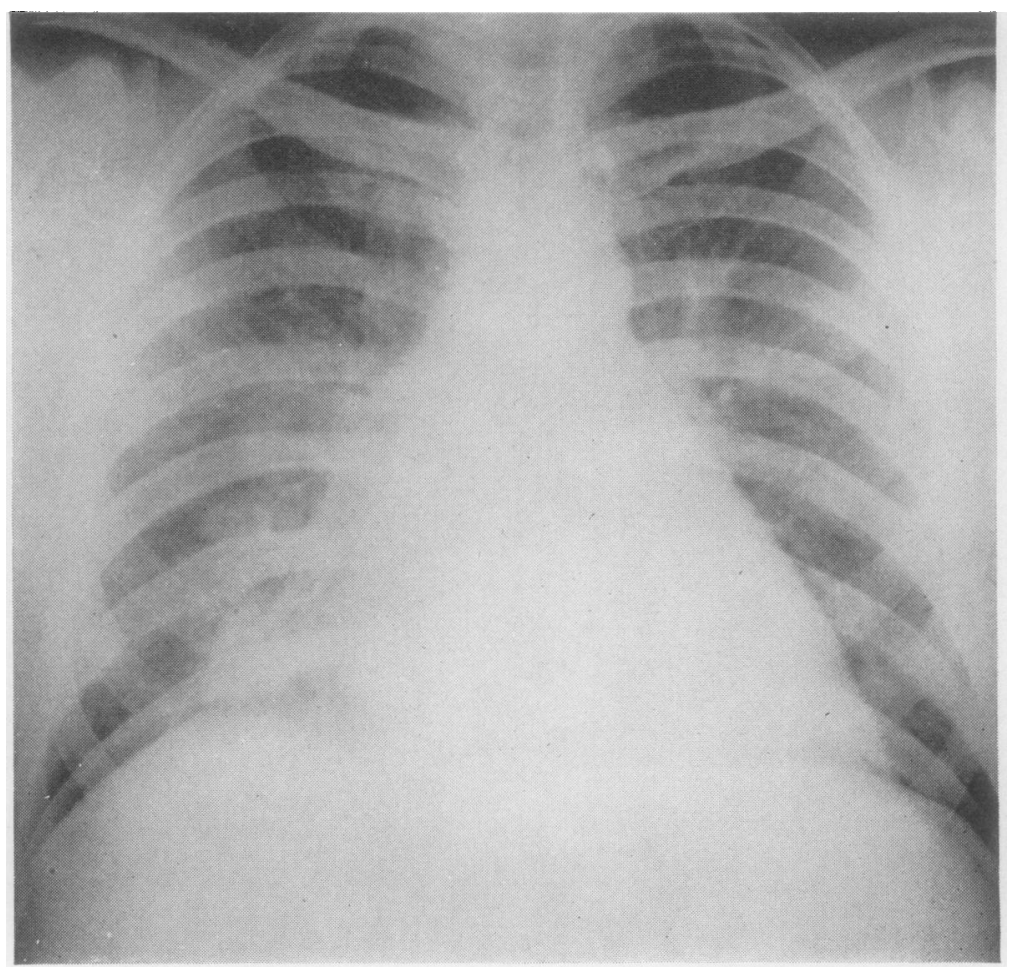




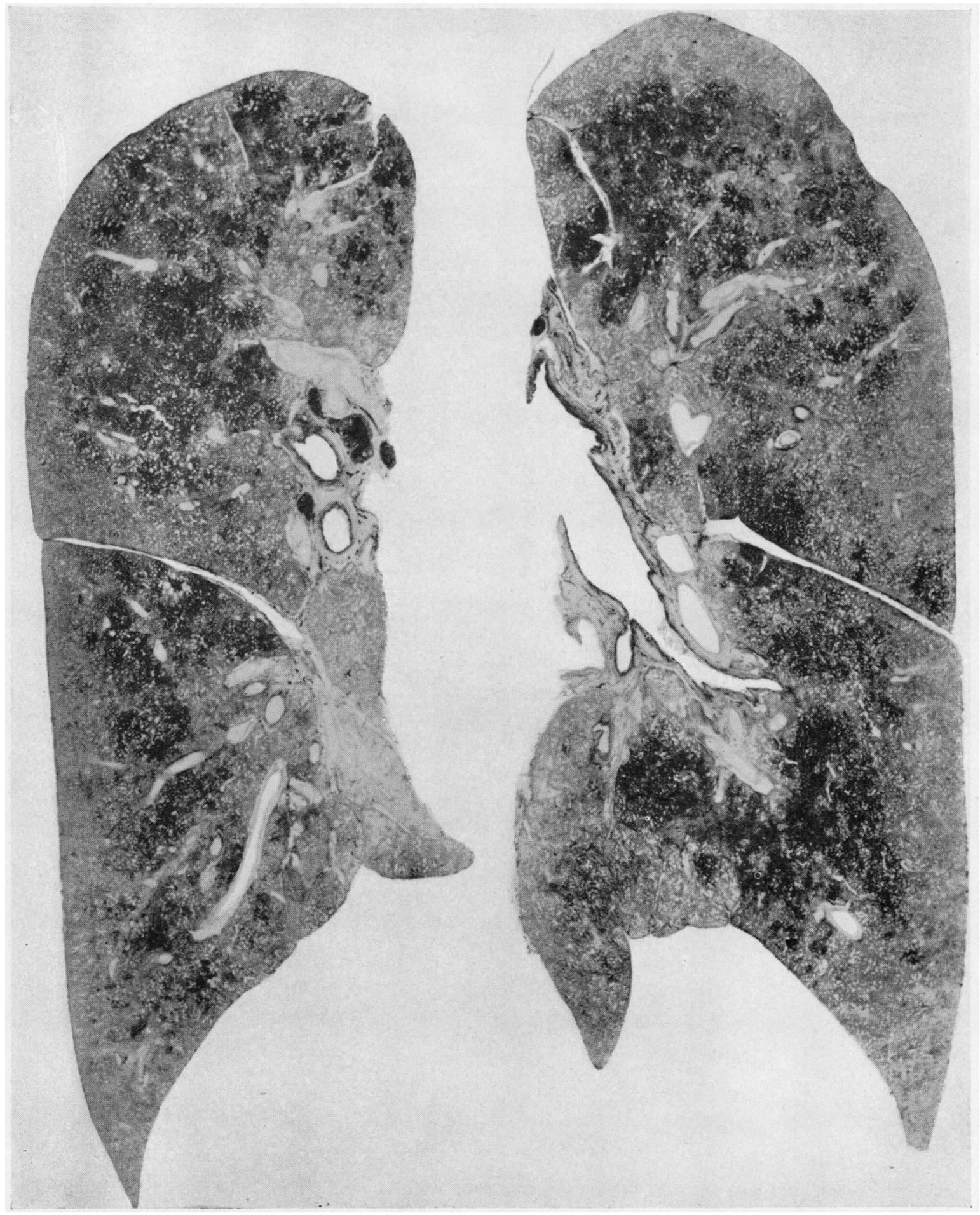

FIG. 13. Case 6. Coronal mounted sections of right and left lungs. Medullary haemorrhages and consolidation. 


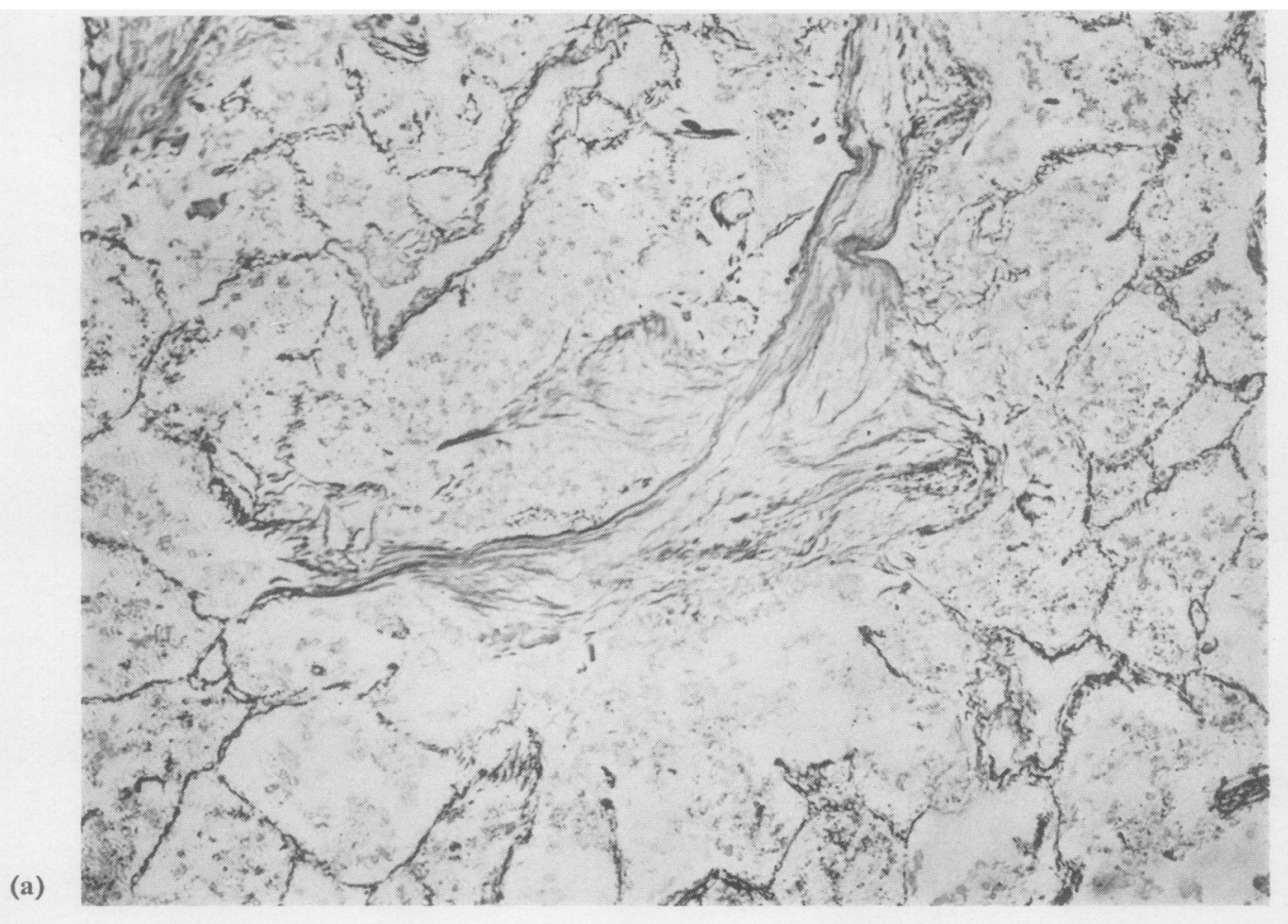

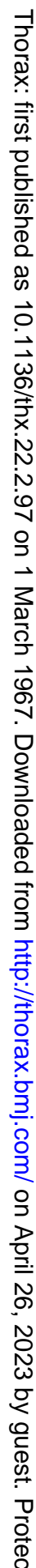
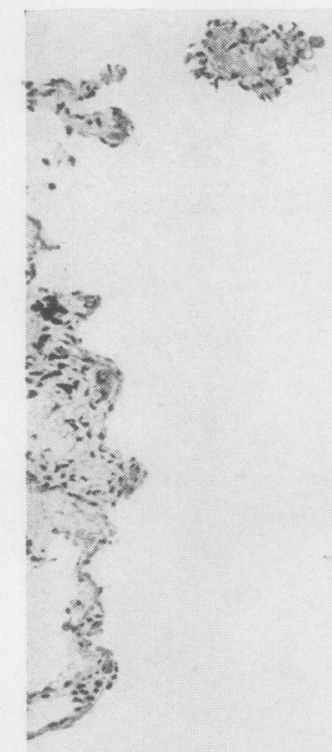

(b) $\frac{13}{3}$

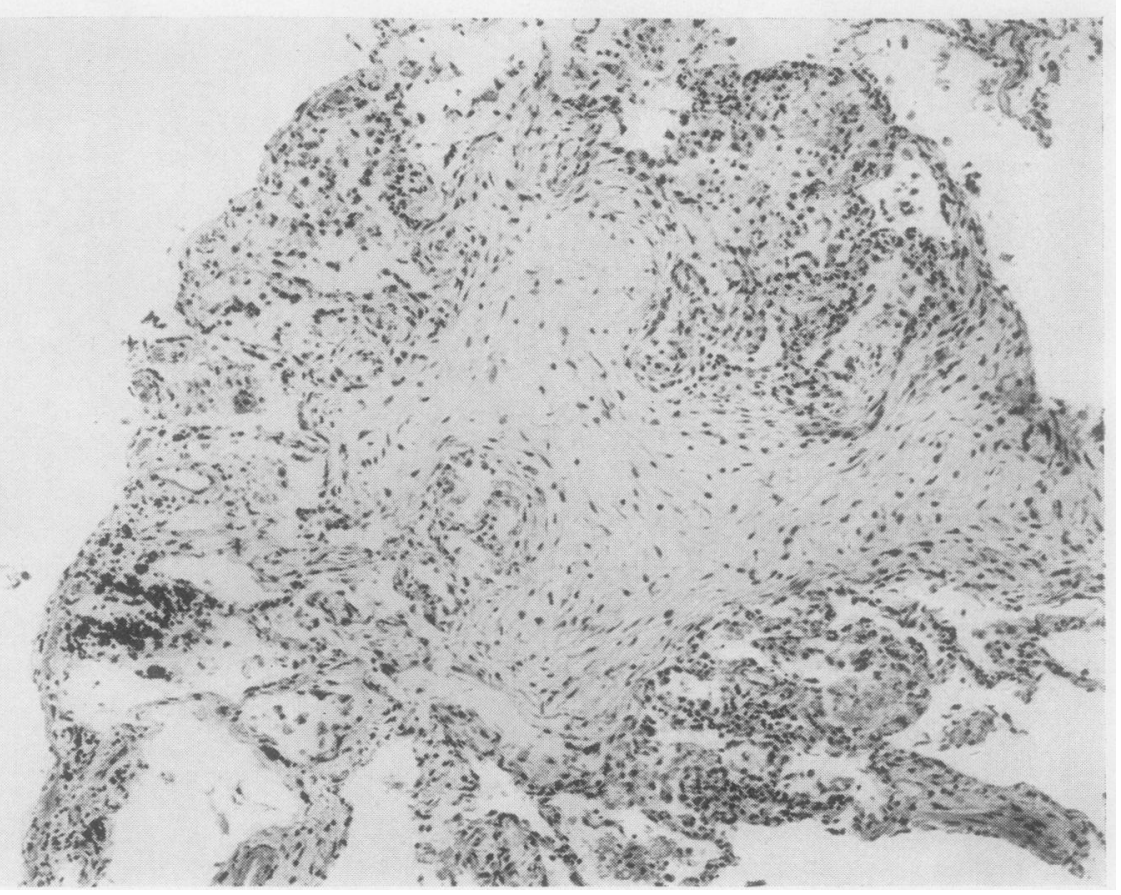

FIG. 14. Case 6. (a) Alveolar duct exudate showing early organization. The reticulin pattern of the alveolar walls is normal. Reticulin stain $\times 150$. (b) A focus of cellular fibrous tissue adjacent to a respiratory bronchiole. $H$. and $E . \times 90$. 
some variants, including unilateral wing-shaped opacity, butterfly accentuation within diffuse pulmonary opacity, and an early right lower zone opacity in a case demonstrating butterfly lesions at necropsy. In general the right lung shows earlier and more extensive changes.

The gross appearance and consistency of the lungs at necropsy conform with previous accounts of 'uraemic oedema' (Doniach, 1947) in which the rubbery texture or 'solid oedema' is characteristic. Some variation was observed, depending on the amount of haemorrhage, varying from small foci to an extensive central process. The cut surface in one case had a gelatinous appearance, and this feature has also been described (Doniach, 1947 ; Zettergren, 1955). This property is not so obvious in lungs fixed and inflated by formol-saline.

Microscopy has confirmed previous studies reported by Doniach (1947), Bass and Singer (1950), Bass, Greenberg, Singer, and Miller (1952), Zettergren (1955), Batolo (1957), Hopps and Wissler (1955), and Schneiter (1961), but there is variation from case to case and in different areas of lung. The changes represent single or repeated episodes of exudation of protein-rich exudate into the alveoli associated with varying amounts of terminal haemorrhage. Secondary changes in the form of alveolar cell desquamation, mononuclear macrophage reaction, and fibroblastic invasion of the exudate contribute to the evolution of a subacute pneumonia. The amount of haemorrhage, not accompanied by haemosiderosis, is greater in some cases than is suggested by previous accounts. The march of events from acute exudation to foci of subacute and chronic pneumonia described in detail by Schneiter (1961) is revealed in some areas in the lungs of the cases described here.

In addition to the fibrinous component much of the 'fibrinoid' tinctorial quality of the alveolar content is due to products of alveolar cell desquamation and breakdown. Granules of PAS-positive material appearing in these cells together with fat globules are liberated into the alveolar spaces. The residual or chronic lesions appear to be of two main types, (1) rounded hyaline structures which are well circumscribed and coated by a single layer of flat endothelial cells, and (2) organized casts of alveoli, ducts, and bronchioles, some of which reveal marked cellularity. These structures bring to mind the 'Masson bodies' and 'bourjeons conjunctifs' described in rheumatic pneumonia by Masson, Riopelle, and Martin (1937) and 'bronchiolitis obliterans' (Ehrich and McIntosh, 1932).
In the series of 67 cases of azotaemic patients examined at necropsy we have encountered 10 cases $(14 \%)$ of uraemic pneumonia in various phases. It is intended to describe these cases elsewhere, but it is noted here that this pneumonic change was generally associated with severe hypertension, hypertensive heart disease, and severe destructive renal disease, i.e., acute and chronic glomerulonephritis and chronic pyelonephritis. Our results are consistent with the views of the majority of authors in suggesting that uraemic pneumonia is the result of single or repeated episodes of left ventricular failure in uraemia in the presence of factors modifying pulmonary capillary permeability. The incidence does not appear to be determined by the degree or duration of azotaemia.

The morphological features of uraemic pneumonia are not specific to uraemia. There are similarities in 'rheumatic pneumonia' (Doniach, 1947), influenzal, streptococcal pneumonia, inhalation of noxious gases, and early radiation pneumonia (Bass et al., 1952). In some cases of left ventricular failure in the absence of uraemia, similar fibrin-rich exudate may occur (Lendrum, Scott, and Park, 1950), but in our experience the uraemic cases show proportionately larger areas of involvement and associated alveolar haemorrhage. In large section studies the characteristic butterfly or medullary pattern has only been observed in one non-uraemic case in which the pathology was haemorrhagic, suppurative pneumonia associated with aortic valvular disease and left ventricular failure.

CORRELATION Correlation between the butterfly density and the post-mortem appearance of the lungs is usually poor for several reasons. Terminal bronchopneumonia, gravitational migration fluid, collapse of the lung, and confluence of abnormal areas impair the identification of possible anatomical boundaries. This is true particularly in the presence of extensive terminal watery pulmonary oedema. The distribution of congestion and haemorrhage may, however, be revealed in sections of the entire lung prepared by the GoughWentworth technique. In their paper defining the differences between the lobar 'medulla' and 'cortex', Herrnheiser and Hinson (1954) showed two examples of medullary haemorrhages by means of sections from cases which had demonstrated the butterfly lesion during life. In one of our cases it has been shown that large sections revealed only focal haemorrhages in a lung extensively involved by organizing fibrinous oedema 
and superadded watery oedema. Three cases have reproduced with remarkable clarity the medullary limitation of haemorrhages and the well-defined separation of medullary and cortical zones. In the large sections there is a clear demonstration that the anatomical units which contribute to the architectural pattern of the medullary haemorrhage are the secondary lobules. The line of demarcation between the medulla and clear periphery is seen in some parts to be composed of distal boundaries of secondary lobules. The lobular contribution is accentuated, too, by the broadened interlobular septa and because all the lobules are not equally involved.

In the sagittal sections it is noteworthy that the haemorrhagic process extends through to the periphery in the anterior and upper zones, and in both coronal and sagittal planes the process extends to the major fissures in the medullary zones. These observations, albeit on a small number of cases, suggest that cortico-medullary division is more accurately represented by the lung as a whole as visualized by Engel (1947) and not by individual lung lobes as implied in the concept of Herrnheiser and Hinson. That the corticomedullary division of the lung does not represent a constant plane is suggested by the differing thickness of cortex in the two large sections shown here (Figs 4 and 9). It is confirmed, however, that butterfly densities represent pathological changes predominantly localized to the lung medulla and that secondary lobular boundaries are the important anatomical structures defining the perimeter.

RESOLVING OPACITIES Butterfly densities resolving over a period of a few days cannot easily be attributed to the haemorrhagic and fibrinous oedema with organization observed in our necropsy series, and neither can they be due exclusively to cardiac decompensation. Cases 1 and 2 have shown regression of opacities following relief of urinary obstruction and the diuretic phase of acute glomerulonephritis. In neither case was the degree of azotaemia considered to be an important factor. The pathology underlying these densities may well be vascular congestion and readily reabsorbed alveolar oedema consequent upon hydraemia and hypervolaemia. For these cases the term 'fluid lung', proposed by Alwall et al. (1953) and Olsson (1954), is more appropriate than 'uraemic oedema' or 'uraemic pneumonia'. These workers have studied the chest radiographs of numerous patients undergoing treatment by ultra-filtration for anuric and oliguric renal failure. In their cases resolution of pulmonary opacities occurred in parallel with elimination of excess fluid, although heart failure was not excluded as a contributory factor since it might occur as a result of overhydration. But Davies (1951), while noting that pulmonary oedema and evidence of congestive heart failure in acute nephritis disappeared at a rate directly proportional to diuresis, found that cardiac output was normal throughout. Holzel and Fawcitt (1960) have also shown that more varied and changeable patterns of lung opacities in children with acute nephritis may be explained on a basis of hydraemia. Henkin, Morton, and Murray (1962) doubt whether this is a satisfactory explanation because they noted regression of lung opacities in the presence of a positive net fluid balance in one patient undergoing treatment by peritoneal dialysis. Although this inconsistency could perhaps be explained by redistribution of body fluids, they favoured a direct uraemic effect on the pulmonary vasculature.

In our necropsy study it was found that the lungs of 21 cases $(31 \%)$ were extensively involved by watery or weakly albuminous oedema consistent with the diagnosis of 'fluid lung'. These examples occurred in renal and extrarenal uraemia from miscellaneous causes, and in both normotensive and hypertensive subjects. It was concluded that 'fluid lung' might occur in all forms of uraemia associated with fluid retention, whereas the pathological changes of uraemic pneumonia were exclusive to a small proportion of severely hypertensive cases, with evidence strongly suggestive of left heart failure.

There are, therefore, good grounds for attributing some transitory butterfly densities in uraemia to the correction of fluid imbalance, but it is reasonable also to invoke the relief of heart failure in other cases. This was true in one of $ᄋ$ Doniach's cases, and similarly Bass and Singer (1950) found that extensive shadows might disappear when left ventricular failure was alleviated.

NON-SPECIFICITY It has been made abundantly clear in the literature that the butterfly density is not specific to uraemia (Doniach, 1949; Jackson, 1951). It is recognized as the classical appearance of acute pulmonary oedema (Nessa and Rigler, 1941) and it occurs almost invariably in patients in whom an attack of severe dyspnoea complicates an illness in which strain is being thrown on the left side of the heart (Hodson, 1950). Thus it may be observed in conditions associated with severe hypertension (e.g., chronic renal disease and polyarteritis nodosa), myo- 
cardial infarction, and in some cases of mitral stenosis. In our experience the opacities in uraemic patients may be more dense and show better definition than in non-uraemic cases. Zdansky (1933) and Roubier and Plauchu (1933) thought the uraemic cases were quite distinctive, but Gould and Torrance (1955) considered that uraemic and non-uraemic cases could not be consistently differentiated.

Sante and Wyatt (1951) have drawn attention to pulmonary changes attributed to hypersensitivity in disorders of connective tissue, drug sensitization, and transfusion of incompatible blood. Some of their examples revealed butterfly shadows which, unlike cases of cardiac failure, were not accompanied by enlargement of the cardiac shadow. This 'antigenic pneumonia' is an important consideration in differential diagnosis and also suggests a contributory immuno-allergic element in other pathological processes showing anatomical restriction to the central and perihilar zones of the lung.

An account of centrally located pulmonary oedema by Buchtala (1950) is concerned with intracerebral causes, including injury to the brain, epilepsy, rapid elevation of intracranial pressure, and peripheral reflex causes illustrated by traumatic injury to the chest and sudden immersion in water without aspiration.

ASSJCIATED SYMPTOMS The symptom of dyspnoea was present in all the cases described here, but it is noted that in uraemia the butterfly lesion is not always accompanied by symptoms or signs of pulmonary oedema. Werkenthin (1939) attributed these opacities to 'latent' or 'subacute' pulmonary oedema. The lack of consistency between the extent of pulmonary opacities and the absence of clinical manifestations is one property which seems to be exclusive to very few uraemic cases.

DISTRIBUTION The explanation for the restricted distribution of the butterfly density is still rather controversial. We believe that the distribution is determined by a non-specific haemodynamic process which is operative in all forms of central pulmonary oedema and that it is not essential to implicate a specific uraemic mechanism to explain the distribution of 'fluid lung' and 'uraemic pneumonia'. This is not the generally accepted view, however, and a number of interesting theories have been advanced. Drinker (1945), for example, suggested that the acidotic respiration of uraemic patients promotes increased drainage of the lung periphery where the amplitude of expansion is greater than the hilum. If this is so, it is difficult to explain why in our cases (Figs 4 and 9) the clear peripheral zones exist in areas of relatively less mobility. The apex and posterior paravertebral margins are considered to be among the least mobile zones (Evans, 1945), whereas the anterior part of the upper zone is more expansible.

Borgström, Ising, Linder, and Lunderquist (1960) have suggested that uraemic pulmonary oedema is due in the first instance to increased 'bronchial capillary oedema' resulting from uraemic toxaemia. Hydraemia and cardiac decompensation might be enhancing the factors. Although the distribution of the bronchial arteries and their capillaries bears some relation to that of the butterfly density, it is difficult to appreciate why uraemic toxins should selectively damage these vessels without damaging systemic capillaries elsewhere. Also, a systemic toxin might be expected to produce symmetrical change to both lungs, but this is not always so. Prolonged and severe grades of uraemia can occur without the emergence of pulmonary lesions, and overt vascular damage to the bronchial arterial system in uraemia is extremely rare. The Borgström theory does not explain the restriction of butterfiy densities occurring in the absence of uraemia.

The observation of peripheral ischaemia of the lung under experimental conditions by Prichard, Daniel, and Ardran (1954) may have an important bearing on the problem, since it suggests the possibility of physiological restriction of blood flow to peripheral lobules. It has been shown that the volume of the peripheral vascular bed may be reduced in conditions where strain is thrown on the left ventricle (James, Owen, and Thomas, 1960), e.g., in systemic, hypertensive coronary artery disease and aortic stenosis. It is still rather speculative whether peripheral vascular ischaemia and possible medullary shunting occur as a reflex mechanism initiated by pulmonary venous hypertension and thus prevent peripheral capillary hypertension and alveolar exudates or transudates.

Perhaps alterations of the normal haemodynamic response as a result of existing vascular disease may interfere with this mechanism and so modify the distribution of acute and subacute pulmonary oedema. In this context some important information has been obtained from studies of pulmonary oedema and vascular changes associated with mitral stenosis. It is known that central pulmonary oedema may complicate mitral 
stenosis (Jackson, 1951), especially in pregnancy, but rarely when long-standing heart failure is associated with gross left ventricular dilatation. In a pathological study Parker (1958) found that central pulmonary congestion occurs when arterial changes are minimal. On the other hand, apical congestion was observed in association with abnormal arteries in the lower portions of the lung showing hypertrophied media and an abnormal amount of intimal thickening. Harrison (1958) also makes the point that upper region congestion and oedema in mitral stenosis occurs because the lower region arteries, with increased tonus and strength resulting from greater muscle hypertrophy, diminish the load on the capillaries which they supply.

It has been shown in cases 3 to 6 that uraemic pneumonia in severely hypertensive subjects adopts the characteristic butterfly distribution. If this distribution is the result of a haemodynamic mechanism and not a function of uraemia per se it is not unreasonable to expect that, when uraemic pneumonia complicates long-standing mitral stenosis, it should occupy the same distribution as pulmonary oedema resulting from mitral stenosis in the absence of uraemia, i.e., upper zonal or apical.

The following case report with the accompanying large lung section shows that this can in fact occur.

Case 7 A woman aged 73 years was admitted to Belvidere Hospital, Glasgow, on 19 October 1965 with breathlessness at rest of three days' duration. For three years she had been treated for heart failure with episodes of dyspnoea. On admission she was distressed and breathing rapidly; there was oedema of the legs and sacrum, auricular fibrillation, audible wheezes and crackling sounds over both lungs, and a blood pressure of approximately $90 / 65 \mathrm{~mm}$. $\mathrm{Hg}$.

A chest radiograph showed enlargement of the heart with a prominent left atrium. Bilateral groundglass opacities involving the upper and middle zones were seen. Blood urea $472 \mathrm{mg}$. $/ 100 \mathrm{ml}$. Blood $p \mathrm{H}$ $7 \cdot 12, \mathrm{CO}_{2}$ tension $27 \mathrm{~mm}$. $\mathrm{Hg}$ (before death $p \mathrm{H} 6 \cdot 6$; $\mathrm{CO}_{2}$ tension $>150 \mathrm{~mm}$. $\mathrm{Hg}$ ). The patient died in coma 20 hours after admission.

The necropsy findings were as follows: (1) moderately severe mitral stenosis ; (2) severe acute pyelonephritis ; (3) rubbery consolidation of the upper lobes of the lung, the cut surfaces appearing gelatinous. Large sections revealed an upper zone haemorrhagic process extending to the pleural surface (Fig. 15). The pleura was normal on each side.

On microscopical examination the upper lobes showed haemorrhagic albuminous and fibrinous alveolar oedema. Many alveolar ducts were dilated and lined by laminated fibrin and granular proteinous material appearing as 'hyaline membrane'.
Some alveolar spaces were lined by prominent hyper- $\overline{\bar{\sigma}}$ plastic alveolar cells and others contained desquamated alveolar cells and mononuclear macrophages. The lower lobes showed thin avaszular alveolar capillaries and areas of irregular interstitial thicken-

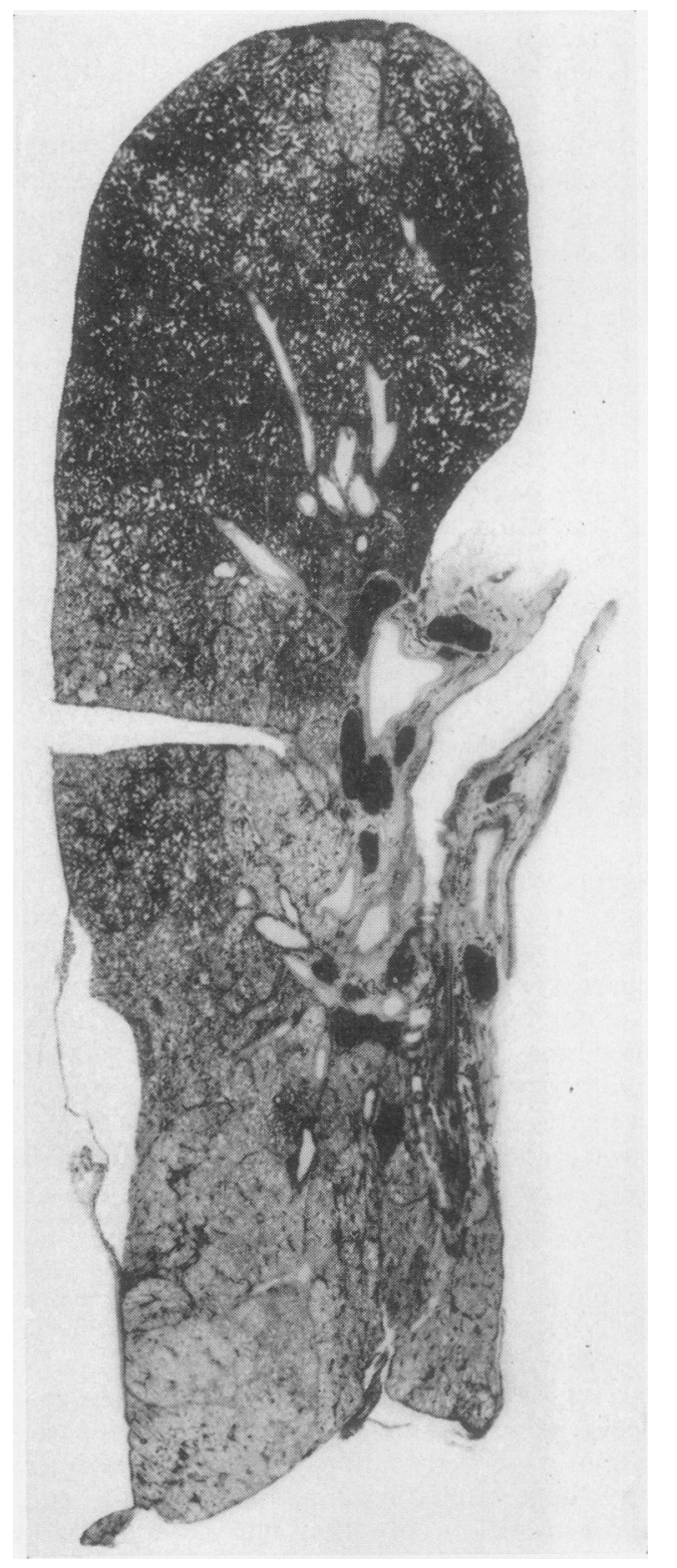

FIG. 15. Case 7. Female aged 73 years. Coronal mounted section of whole lung (right). The patient $\stackrel{\mathbb{Q}}{\Omega}$ had mitral stenosis and died in uraemia. The distribu-o tion of haemorrhagic uraemic pneumonia was upper zonal and involved the periphery of both upper lobes. O 
1ng of alveolar walls. Both arteries and veins in the lower zones showed thickening of the media and hyaline changes. Small aggregates of haemosiderinladen macrophages were present.

Comment: This patient had mitral stenosis and died in uraemia with severe acidosis. Pulmonary changes consistent with early uraemic pneumonia were present in both upper zones, including the peripheral zones.

It follows from this case report that factors which influence the distribution of pulmonary oedema in non-uraemic subjects also apply to uraemic pneumonia, and the role of uraemic factors in localizing pathology to the perihilar zones of the lung may therefore have been erroneously assumed. The ultimate solution to what has been described as the enigma of the butterfly density lies in understanding the wider field of pulmonary haemodynamics associated with pulmonary oedema from any cause. Uraemia becomes relevant to this problem because it may include circumstances in which non-specific mechanisms are brought into play as, for instance, in the presence of hypertensive heart disease, fluid retention, and cerebral oedema. More pertinent to uraemic states are the reasons for increased pulmonary capillary permeability, the failure to resolve pulmonary exudates, and their subsequent chronicity.

My thanks are due to the clinical staff of the Cardiff United Hospitals and Belvidere Hospital, Glasgow, for permission to publish data from their case records. For allowing me to study their reports and necropsy material I am indebted to Dr. G. $\mathbf{H}$. Roberts (case 5) and Dr. H. J. Whiteley (cases 3 and 6). Help given by the technical staff at the Institute of Pathology and the photographic departments at the Institute of Pathology and the Royal Infirmary, Cardiff, is gratefully acknowledged.

I wish to thank Professor J. Gough for his advice and encouragement and for permission to publish Figs 4, 9, 10, and 13.

Cases 1 to 6 were included in a thesis accepted for the degree of M.D. (London).

\section{REFERENCES}

Allen, A. C. (1951). The Kidney, p. 67. Grune and Stratton, New York. Alwall, N., Lunderquist, A., and Olsson, O. (1953). Studies on electrolyte-fluid retention. I. Uremic lung-fluid lung? On pathogenesis and therapy. (A preliminary report.) Acta med. scand., 146, 157.

Bass, H. E., and Singer, E. (1950). Pulmonary changes in uremia. J. Amer. med. Ass., 144, 819.

- Greenberg, D., Singer, E., and Miller, M. A. (1952). Pulmonary changes in uremia. Ibid., 148, 724.
Batolo, Di (1957). Sulle alterazioni polmonari nell uraemia. Osservazioni anatomiche e sperimentali. Arch.ital. Anat. Istol.pat., 31, 481.

Borgstrc̈m, K., Ising, U., Linder, E., and Lunderquist, A. (1960) Experimental pulmonary edema. Acta radiol. (Stockh)., 54, 97.

Buchtala, V. (1950). Das zentral bedingte Lungenc̈dem. Fortschr. Röntgenstr., 73, 702.

Davies, C. E. (1951). Heart failure in acute nephritis. Quart. J. Med. N.S. $20,163$.

Doniach, I. (1947). Uremic edema of the lungs. Amer. J. Roentgenol., 58,620 .

- (1949). Uraemic oedema of the lungs. Lancet, 2, 911.

Drinker, C. K. (1945). Pulmonary Edema and Inflammation, p. 54 Harvard University Press, Cambridge, Mass.

Ehrich, W., and McIntosh, J. F. (1932). The pathogenesis of bronchiolitis obliterans; observations in cases of Bright's disease. Arch. Path., 13, 69 .

Engel, S. (1947). The Child's Lung. Arnold, London.

Evans, C. Lovatt (1945). Principles of Human Physiology, 9th ed. p. 682. Churchill, London.

Gough, J., and Wentworth, J. E. (1960). Thin sections of entire organs mounted on paper. In Recent Advances in Pathology, 7 th ed., ed. C. V. Harrison, p. 80. Churchill, London.

Gould, D. M., and Torrance, D. J. (1955). Pulmonary edema. Amer. J. Roentgenol., 73, 366.

Harrison, C. V. (1958). The pathology of the pulmonary vessels in pulmonary hypertension. Symposium: Pulmonary Hypertension. Brit. J. Radiol., 31, 217.

Henkin, R. I., Morton, H. M., and Murray, J. F. (1962). Uremic pneumonitis, a clinical physiological study. Arn. intern. Med., 57, 1001 .

Herrnheiser, G., and Hinson, K. F. W. (1954). An anatomicalexplanation of the formation of butterfy shadows. Thorax, 9, 198.

Hodson, C. J. (1950). Pulmonary oedema and the 'batswing' shadow. J. Fac. Radiol. (Lond.), 1, 176.

Holzel, A., and Fawcitt, J. (1960). Pulmonary changes in acute glomerulonephritis in childhood. J. Pediat., 57, 695.

Hopps, H. C., and Wissler, R. W. (1955). Uremic pneumonitis. Amer. J. Path., 31, 261.

Jackson, F. (1951). The radiology of acute pulmonary oedema. Brit. Heart J., 13, 503.

James, W. R. L., Owen, G. M., and Thomas, A. J. (1960). The small pulmonary arteries studied by a new infection method. Ibid., 22, 695 .

Lelong, M., and Bernard, J. (1937). L'image radiologique d'un cas d'oedème aigu du poumon d'origin rénale chez un enfant. Bull. Soc. med. Hôp. Paris, 53, 177.

Lendrum, A. C., Scott, L. D. W., and Park, S. D. S. (1950). Pulmonary changes due to cardiac disease with special reference to haemosiderosis. Quart. J. Med., N.S. 19, 249.

Marchand, P. (1951). The anatomy and applied anatomy of the mediastinal fascia. Thorax, 6, 359.

Masson, P., Riopelle, J. L., and Martin. P. (1937). Poumon rhumatismal. Ann. Anat. path., 14, 359.

Nessa, C. B., and Rigler, L. G. (1941). The roentgenological manifestations of pulmonary edema. Radiology, 37, 35 .

Olsson, O. (1954). Some radiological problems connected with Bright's disease. Brit. J. Radiol., 27, 86.

Parker, R. A. (1958). Vascular and congestive changes of the lung in mitral stenosis. Stanf. med. Bull., 16, 87.

Prichard, M. M. L., Daniel, P. M., and Ardran, G. M. (1954). Peripheral ischaemia of the lung. Some experimental observations. Brit. J. Radiol., $27,93$.

Rendich, R. A., Levy, A. H., and Cove, A. M. (1941). Pulmonary manifestations of azotemia. Amer. J. Roentgenol., 46, 802.

Roubier, C., and Plauchu, M. (1933). Sur certains aspects radiographiques de l'oedeme pulmonaire chez les cardiorénaux. Lyon méd., 152, 137.

Sante, L. R., and Wyatt, J. P. (1951). Roentgenological and pathological observations in antigenic pneumonitis. Its relationship to the collagen diseases. Amer. J. Roentgenol., 66, 527.

Schneiter, R. (1961). Pneumonies urémiques aiguë et chronique. Ann. Anat. path., N.S. 6, 59.

Werkenthin, M. (1939). The roentgenological aspect of lung edema. Amer. J. Roentgenol.. 41, 183.

Zdansky, E. (1933). Über das Rëntgenbild des Lungenödems, gleichzeitig ein Beitrag zur Frage der Pathogenese des Lungenödems. Röntgenpraxis, 5, 248.

Zettergren, L. (1955). Uremic lung. Report of four cases reaching autopsy. Acta Soc. Med. upsalien., 60, 161. 